Eurpopera

Addiction

Research

\section{Evaluation of Treatment}

Eur Addict Res 2002;8:1

\title{
Editorial
}

\author{
Christian Haasen, Hamburg
}

In evaluating treatment outcome of different addiction services, researchers are faced with a number of major difficulties. These difficulties include having to assess subjective and objective factors affecting treatment outcome, the lack of standardised measures for assessing treatment outcome in different settings, and the influence of variables associated with the different types of addiction disorders as well as subsamples of patients for each disorder category. The diversity of factors affecting outcome leads us to continuously reconsider evaluation studies, which will take different angles of evaluating treatment outcome for different groups in different settings; and as the addiction field is showing a tendency towards more diversification, the area of evaluation research becomes more and more complicated.

After the special topic on the evaluation of alcohol addiction treatment in vol. 7, No. 2 of European Addiction Research, this issue will focus on evaluating treatment outcome of addiction services for illicit drugs. The first paper by De Weert-Van Oene et al. presents a methodological focus on those variables associated with treatment outcome that can be described as subjective patient variables - motivation for treatment. Instruments developed to assess such variables need to be validated in Europe if they were initially developed in the US, since motivation for treatment is strongly associated with cultural norms and values and therefore will differ from one country to the next. Nonetheless, the scale assessed by De Weert-Van Oene et al. showed consistency despite cultural barriers. This type of instrument evaluation can serve as an example for future methodological evaluation.
The second paper by Vanderplasschen et al. attempts to evaluate variables associated with treatment outcome and variables which concern the structure and organisation of addiction services. This paper touches upon another area that is gaining importance: the area of quality control. The necessity for research in this field is gaining importance also for economic reasons, as there are several findings pointing to the effectiveness of systematising treatment options and implementing models of case management. However, treatment outcome has to be the main variable in directing any changes in addiction services, while economic considerations need to follow treatment outcome in importance.

The third paper by Fernández-Hermida et al. addresses the most complex area of treatment outcome evaluation, which is the long-term outcome. It is widely accepted that recovery from addiction involves a longterm process, but most treatment outcome studies are rather short-term oriented. Therefore, by presenting a long-term project, the focus shifts from immediate treatment effects to other dimensions such as changes in the family situation, education and employment and draws our attention to these important aspects. The three papers obviously can only show a small part of the overall evaluation research field, but a presentation of three very different approaches in three different European countries (The Netherlands, Belgium, Spain) gives us an insight into the diversity of research in Europe in this area.

\begin{tabular}{ll}
\hline KARGER & ( 2002 S. Karger AG, Basel \\
1022-6877/02/0081-0001\$18.50/0 \\
$\begin{array}{l}\text { Fax +41613061234 } \\
\text { E-Mail karger@karger.ch } \\
\text { www.karger.com }\end{array}$ & $\begin{array}{l}\text { Accessible online at: } \\
\text { www.karger.com/journals/ear }\end{array}$
\end{tabular}

